\title{
Mental health, smoking and poverty: benefits of supporting smokers to quit
}

\author{
Vicky Salt, ${ }^{1} \odot$ Ciaran Osborne ${ }^{1}$
}

BJPsych Bulletin (2020) 44, 213-218, doi:10.1192/bjb.2020.88

${ }^{1}$ Action on Smoking and Health, UK Correspondence to Vicky Salt (vicky.salt@ash.org.uk) First received 16 Dec 2019, final revision 24 Jun 2020, accepted 2 Jul 2020

(c) The Author(s), 2020. This is an Open Access article, distributed under the terms of the Creative Commons Attribution licence (http:// creativecommons.org/licenses/by/4. $0 /$ ), which permits unrestricted re-use, distribution, and reproduction in any medium, provided the original work is properly cited.
Smoking rates among people with common mental health conditions remain around $50 \%$ higher than those in the wider population; this is a significant cause of the 10-20-year reduced life expectancy of people with mental health conditions. However, the effects of smoking go far beyond physical health. Research estimates that smokers with mental health conditions could be spending as much as $€ 2200$ a year on tobacco, pushing an estimated 130000 people with a common mental disorder into poverty. The Government has set a target for England to be smokefree by 2030; however, without a dramatic increase in support, smokers with mental health conditions risk being left behind. Action on Smoking and Health provides the secretariat for the Mental Health \& Smoking Partnership. The Partnership aims to reduce the inequality in smoking rates between people with mental health conditions and the wider population. It brings together Royal Colleges, third-sector organisations, trade unions and academia to review progress and highlight areas for further action.

Keywords Smoking; poverty; inequality; physical health; education and training.

\section{The challenge}

People with mental health conditions die on average 10-20 years earlier than individuals in the wider population. ${ }^{1}$ High smoking rates are one of the key reasons for this health inequality. ${ }^{2}$ Smoking rates remained largely static among people with mental health conditions during the 20 years from 1993 to 2013, at around $40 \% .^{3}$ Although new figures suggest that this prevalence is starting to decline, smoking rates among people with common mental health conditions remain around $50 \%$ higher than those in the wider population. $^{4,5}$

However, the effects of smoking go far beyond reduced life expectancy; it influences employment prospects, ${ }^{6}$ reduces earnings, ${ }^{6}$ increases care needs ${ }^{7}$ and causes poverty. ${ }^{8}$ Higher smoking rates are associated with every indicator of disadvantage, but most adult smokers want to quit. ${ }^{9}$ Smokers with mental health conditions are aware of the risks to people around them from second-hand smoke and see this as a motivator to quit; clinicians must offer support to enable them to do so.

The challenge of The Mental Health and Smoking Partnership is to help tackle these inequalities. ${ }^{10}$ The Partnership was established in 2016 following publication of The Stolen Years: The Mental Health and Smoking Action Report by Action on Smoking and Health (ASH), with the ambition of reducing smoking prevalence to $5 \%$ or less among people with mental health conditions. ${ }^{11}$ The report sets out the sector-wide action needed to reduce smoking rates among people with mental health conditions, from reviewing the training of the mental health workforce to building the research base on peer support and expert-by-experience-led interventions.

Three years on, the Government has published the Tobacco Control Plan for England, ${ }^{12}$ NHS Long Term Plan $^{13}$ and Prevention Green Paper, ${ }^{14}$ committing to reducing smoking prevalence among people with mental health conditions. However, change is not happening quickly enough. The recent Green Paper Advancing our Health: Prevention in the 2020 s sets an ambition to end smoking in England by 2030, defined as a prevalence of $5 \%$ or less. ${ }^{14}$ To achieve this, using the latest publicly available data, ${ }^{15}$ it is estimated that the annual rate of decline from 2014-2030 among people with mental health conditions needs to be an ambitious 1.82 percentage points a year, more than double the previous rate of decline. Unless we dramatically increase the support available, this target will not be met, and people with mental health conditions will be left behind.

\section{Tobacco, health and poverty}

In his landmark 2010 report, Fair Society, Healthy Lives, Michael Marmot made clear the moral dimension of tackling health inequalities: 'Inequalities are a matter of life and death, of health and sickness, of well-being and misery. The fact that in England today people from different socioeconomic groups experience avoidable differences in health, well-being and length of life is, quite simply, unfair and unacceptable'. 16

Half of all lifetime smokers will die from their addiction, that is, more than 96000 people every year in the UK. For 
every smoker who dies, an estimated 30 others will be living with smoking-related diseases. ${ }^{17}$ This should be reason enough to act.

However, there are also short-term, immediate benefits to quitting smoking. Smoking decreases disposable income (defined as household income after tax and National Insurance contributions), which can be returned to the household when smokers quit. Smokers in social housing spend, on average, $14.6 \%$ of their disposable income on tobacco, compared with $6.9 \%$ among owner occupiers and $5.8 \%$ of those living in privately rented accommodation. ${ }^{18}$ This has substantial economic consequences, with more than 1 million people - including 263000 children - living in poverty as a direct result of income lost to expenditure on tobacco. The proportion of social housing tenants living in poverty increases from around a quarter (28.3\%) to two in five (42.8\%) once the costs of smoking are considered. ${ }^{8}$

Research commissioned by ASH and Public Health England has shown the extent to which people with mental health conditions are economically disadvantaged due to smoking. ${ }^{19}$ Higher rates of smoking are found among people with a mental health condition living in poverty (Table 1). Looking at the number of cigarettes smoked and taking into account purchases of illicit and cheap tobacco, researchers estimate that smokers in poverty spend an average of around $£ 1200$ a year on smoking, at 2015 prices. $^{19}$ However, adjusting for underreporting of the amount of tobacco smoked, smokers with a mental health condition below the poverty line could be spending over £2200 a year on tobacco. ${ }^{19}$

Using the conservative estimate of $£ 1200$, researchers estimate that around 130000 people with a mental health condition are pushed into poverty by expenditure on tobacco. Table 2 shows a breakdown of smokers with common mental disorders, those taking psychoactive medications and those with longstanding mental disorders across the UK, who are pushed into poverty by expenditure on tobacco. $^{19}$

The effects of expenditure on tobacco are compounded by lower earnings among smokers in employment, with non-smokers earning on average $6.8 \%$ more than smokers. Smokers are also significantly less likely to be in employment than never-smokers. Long-term smokers are $7.5 \%$ less likely to be in employment than never-smokers.

People with mental health conditions are more likely to be unemployed, to receive benefits and to be living in

\begin{tabular}{|lll|}
\hline Table 1 & $\begin{array}{l}\text { Smoking prevalence according to mental health } \\
\text { disorder and poverty }\end{array}$ \\
$\begin{array}{l}\text { Type of disorder } \\
\text { reported }\end{array}$ & $\begin{array}{l}\text { Smoking } \\
\text { prevalence in whole } \\
\text { population }\end{array}$ & $\begin{array}{l}\text { Smoking prevalence } \\
\text { among those in } \\
\text { poverty }\end{array}$ \\
\hline $\begin{array}{l}\text { Common mental } \\
\text { disorder }\end{array}$ & $34 \%$ & $46 \%$ \\
\hline $\begin{array}{l}\text { Currently taking } \\
\text { psychoactive } \\
\text { medication }\end{array}$ & $34 \%$ & $46 \%$ \\
\hline $\begin{array}{l}\text { Longstanding mental } \\
\text { disorder }\end{array}$ & $40 \%$ & $52 \%$ \\
\hline
\end{tabular}

relative poverty than those without mental health conditions. ${ }^{2,20}$ It is well documented that debt and financial stress can exacerbate mental ill health and that people with mental health conditions are more likely to experience debt problems. ${ }^{21}$ The interactions between smoking, poverty, debt and mental health suggested by these studies are important reasons to support smokers to quit.

\section{Effects on mental health}

Further motivation to support smokers with mental health conditions to quit comes from the positive influence this can have on mental health. Quitting smoking is associated with reduced depression, anxiety and stress, as well as improved positive mood and quality of life compared with continuing to smoke. ${ }^{22}$ For some people with mental health conditions, smoking can feel like 'self-medicating', and people say that it is an important way for them to deal with stress. However, this relief is temporary, linked to relieving withdrawal from nicotine and in the long term it can exacerbate symptoms. ${ }^{23}$ The effect of smoking cessation on anxiety and depression appears to be at least as large as that of antidepressants. ${ }^{22}$

Not only does smoking cessation improve physical health and reduce the chances of developing a smoking-related disease, supporting smokers to quit can also lift them out of poverty, return valuable disposable income to households and improve mental health.

It is also crucial that we remember that a majority of smokers want to quit. ${ }^{9}$ This is true among all smokers, including those with mental health conditions. ${ }^{24}$ An even larger majority $(71 \%)$ of smokers wish they had never started. $^{25}$

\section{Providing support to quit}

This raises the question: are services doing enough to support smokers with mental health conditions to quit? In 2016, the Five Year Forward View for Mental Health set a target for all in-patient mental health services to be smokefree by $2018 .{ }^{26}$ This commitment was reiterated in the Tobacco Control Plan for England, which stated that it would include 'providing integrated tobacco dependence treatment pathways ${ }^{, 12}$ in line with National Institute for Health and Care Excellence (NICE) guidance: Smoking: Acute, Maternity and Mental Health Services (PH48). ${ }^{27}$ There are no specific targets for community mental health services, yet ASH's survey of community mental health practitioners, discussed below, shows that there is a need to focus on the support provided by community mental health teams.

\section{In-patient settings}

This 2018 target has been missed. A 2019 survey of mental health trusts in England found that nearly one in five (18\%) did not have a comprehensive smokefree policy in line with NICE guidance. ${ }^{28}$ Over half $(55 \%)$ of trusts reported not always asking patients about their smoking status on admission, and $57 \%$ of trusts said that staff 


\begin{tabular}{|c|c|c|c|c|c|c|c|c|c|}
\hline & \multicolumn{3}{|c|}{$\begin{array}{l}\text { Common mental disorder } \\
\quad(\text { CIS-R score }>12)\end{array}$} & \multicolumn{3}{|c|}{ Currently taking psychoactive medications } & \multicolumn{3}{|c|}{ Longstanding mental disorder } \\
\hline & $\begin{array}{l}\text { Smokers } \\
\text { with } \\
\text { disorder } \\
\text { who are in } \\
\text { poverty }^{\text {a }}\end{array}$ & $\begin{array}{l}\text { Smokers } \\
\text { with } \\
\text { disorder } \\
\text { who are in } \\
\text { poverty }{ }^{b}\end{array}$ & $\begin{array}{l}\text { Numbers with } \\
\text { disorder } \\
\text { drawn into } \\
\text { poverty by } \\
\text { smoking }^{\text {a }}\end{array}$ & $\begin{array}{l}\text { Smokers } \\
\text { with } \\
\text { disorder } \\
\text { who are in } \\
\text { poverty }^{a}\end{array}$ & $\begin{array}{l}\text { Smokers } \\
\text { with } \\
\text { disorder } \\
\text { who are in } \\
\text { poverty }\end{array}$ & $\begin{array}{l}\text { Numbers with } \\
\text { disorder } \\
\text { drawn into } \\
\text { poverty by } \\
\text { smoking }^{\text {a }}\end{array}$ & $\begin{array}{l}\text { Smokers } \\
\text { with } \\
\text { disorder } \\
\text { who are in } \\
\text { poverty }^{\text {a }}\end{array}$ & $\begin{array}{l}\text { Smokers } \\
\text { with } \\
\text { disorder } \\
\text { who are in } \\
\text { poverty }^{\text {b }}\end{array}$ & $\begin{array}{l}\text { Numbers with } \\
\text { disorder } \\
\text { drawn into } \\
\text { poverty by } \\
\text { smoking }^{\text {a }}\end{array}$ \\
\hline UK & 1217733 & 904647 & 135304 & 553801 & 405282 & 55380 & 717110 & 425420 & 100062 \\
\hline England & 1021983 & 759225 & 113554 & 464778 & 340133 & 46478 & 601835 & 357034 & 83977 \\
\hline Scotland & 103011 & 76527 & 11446 & 46848 & 34284 & 4685 & 60662 & 35987 & 8464 \\
\hline Wales & 58913 & 43767 & 6546 & 26793 & 19607 & 2679 & 34694 & 20582 & 4841 \\
\hline $\begin{array}{l}\text { Northern } \\
\text { Ireland }\end{array}$ & 33825 & 25128 & 3758 & 15383 & 11257 & 1538 & 19919 & 11817 & 2779 \\
\hline
\end{tabular}

CIS-R, revised Clinical Interview Schedule; HBAI, households below average income. a. Poverty based on $60 \%$ median gross income within survey.

b. Poverty based on HBAI poverty threshold.

accompany patients on escorted leave to smoke every day, a practice which is: '...outdated. It reduces the resources available to deliver clinical care ${ }^{29}$ and causes direct harm to patients. ${ }^{, 12}$

Further, although all trusts reported that they offer nicotine replacement therapy (NRT) to patients, only $49 \%$ offered varenicline (Champix). ${ }^{28}$ This is likely to be due in part to historic misunderstandings about the effects of varenicline on mental health. However, evidence shows that varenicline is not associated with negative outcomes for people with mental health conditions. ${ }^{30-32}$ As reflected in the Royal College of Psychiatrists' position statement on prescribing of varenicline: 'varenicline is a generally safe and well-tolerated medication which has been proven to increase rates of smoking cessation in psychiatric and non-psychiatric populations, ${ }^{33}$

However, prescribing rates for varenicline are falling fast, particularly for people with mental health conditions. Primary care data for over 200000 smokers shows that smokers with mental health conditions were $31 \%$ less likely to be prescribed varenicline than NRT, despite varenicline being more effective. ${ }^{32}$ Smokers with mental health conditions who were prescribed varenicline were $19 \%$ more likely to have successfully quit at 2-year follow-up, compared with those prescribed NRT. ${ }^{32}$

These policies must be addressed to ensure that all smokers are being offered the best support available to quit, in line with NICE guidance. Smokers with mental health conditions are often more heavily addicted, ${ }^{2}$ and ensuring they have access to the most effective pharmacotherapy is essential to supporting quit attempts.

ASH's survey also showed significant variation in approaches to vaping, from allowing a range of devices to be used across trusts, to prohibiting the use of e-cigarettes. National guidance from $\mathrm{PHE},{ }^{34}$ the Royal College of Physicians $^{35}$ and the Royal College of Psychiatrists ${ }^{33}$ highlights that vaping is substantially less harmful than continuing to smoke. Under UK regulations, the Medicines and Health Care Products Regulatory Agency (MHRA) oversees notification of new nicotine-containing e-cigarettes and e-liquids, and operates a yellow card reporting system for any adverse reactions. ${ }^{36} \mathrm{~A}$ report is not proof that a reaction was caused by vaping, just that the reporter suspected it might have been. From 20 May 2016 through to 9 January 2020, the MHRA had received 84 yellow card reports on 245 adverse reactions, including 27 serious respiratory events. ${ }^{37}$ In 2019, over 3.6 million people in England were estimated to be using e-cigarettes. ${ }^{38}$

E-cigarettes are the most popular aid to quitting smoking in England, ${ }^{39}$ and research has shown that using an e-cigarette along with behavioural support can be twice as effective for quitting smoking compared with using NRT. ${ }^{40}$ Further, vaping is much cheaper than smoking. Research suggests that smokers who switch to e-cigarettes spend around £417 a year on vaping, substantially less than the estimated expenditure on tobacco of $£ 1200$ a year. ${ }^{41}$ These benefits should not be underestimated, and trusts should review policies in line with the latest evidence ${ }^{37,42}$ and national guidance. ${ }^{43}$

Smokers also want greater provision and variety of support. In a focus group with 12 participants with experience of in-patient services or with family in in-patient services, no participant felt that the support offered on admission to a smokefree in-patient service was sufficient. ${ }^{44}$ They noted that smokefree often felt like a 'tickbox exercise' rather than part of their care, with references to clear failings in the support options available: 'Handing someone a card with a number should not, in my opinion, count as actively giving someone smoking cessation support - that's what I've had. But they can say they've given you some support; the fact that you couldn't use the phone at the time doesn't seem relevant'.

To reduce the inequality in smoking rates between people with mental health conditions and the wider population, it is essential to improve the support offered in in-patient services. There are examples of trusts leading the way on this agenda, offering excellent support and engaging with smokers to ensure that they are addressing the broader social aspects of smoking and not just physiological withdrawal. Public Health England's videos on implementation 
of NICE PH48 illustrate some of these examples. ${ }^{45}$ If we are to achieve a smokefree 2030 for people with mental health conditions, these examples must become the norm.

\section{Community services}

A similarly patchy picture of support is seen in community services, which support the majority of people with mental health conditions. ${ }^{46}$ Although there is less evidence here, a small-scale, self-selecting survey conducted by ASH of 103 mental health nurses (representing 33 trusts) and 171 psychiatrists (representing 48 trusts) found that over 55\% reported receiving no training on supporting smoking cessation. ${ }^{47}$ Only around a quarter of respondents said that they 'always' or 'usually' delivered very brief advice on smoking.

Prescribing medications for smoking cessation was reported to be similarly uncommon in community settings. Three-quarters (76\%) of qualified nurses said that they never prescribed smoking cessation medications (NRT or varenicline), as did three-fifths (59\%) of psychiatrists. ${ }^{47}$

\section{What works?}

This absence of support is concerning, especially as there is a strong evidence base around what works to support smokers to quit. Smokers are three times more likely to quit successfully with the support of a specialist stop-smoking service than when attempting to quit unaided. ${ }^{48,49}$

The Smoking Cessation Intervention for People with Severe Mental Ill Health (SCIMITAR) pilot ${ }^{50}$ and randomised controlled trial (SCIMITAR +$)^{51}$ were built on this evidence base. The SCIMITAR trials tailored the support set out in NICE guidance for people with mental health conditions, showing that such an approach is both effective and cost-effective. SCIMITAR compared the effectiveness of combined behavioural and pharmacological support for smoking cessation with usual care. ${ }^{51}$ Trial-condition participants received face-to-face behavioural support delivered by a trained mental health professional and prescriptions of their choice of smoking cessation medications, the most commonly chosen being NRT. Adaptations for people with severe mental health conditions - including extended prequit sessions, 'cut down to quit', and home visits - were offered in the trial arm. Compared with usual care, this intervention more than doubled quit rates at 6-month follow-up and showed significant improvements after 12 months. ${ }^{51}$

Participants in the SCIMITAR trial reported that the intervention being delivered by mental health nurses was important to them. It was important that they felt this support was being delivered by someone who would understand their mental health diagnosis without judgement and with professional expertise.

An ASH/Rethink focus group participant highlighted clearly the unique part a mental health nurse could play in supporting smokers: 'Community mental health nurses visit people in their own homes, and they see how that person is managing. Smoking's expensive ... if it's the difference between paying your electricity bill and buying a packet of fags... If this person is struggling, the community mental health nurse is in a good position to advise and act as a signpost ... and link with GP services and the local chemists that offer smoking cessation, ${ }^{44}$

This illustrates the value of training mental health professionals to deliver smoking cessation advice and support. However, studies have shown that mental health staff may not see addressing smoking as part of their role. One study found that only $48 \%$ of respondents felt that addressing smoking was within their remit as a mental health professional, ${ }^{52}$ and one in five were not sure whether quitting smoking would have a positive effect on recovery or thought quitting smoking could have negative effects. ${ }^{52}$

The persistence of these myths undermines the potential for mental health services to support smokers to quit, and highlights the need for smoking and smoking cessation to be included in the training of mental health professionals.

\section{Making change happen}

Population-level interventions that have driven down smoking rates nationally have largely failed to reach smokers with mental health conditions. Although the specific commitment to supporting people with mental health conditions to stop smoking in the NHS Long Term Plan is welcome, the pace of change is currently slow. ${ }^{13}$ Transformation funding through the NHS Long Term Plan will not be in place nationally until 2023-2024. ${ }^{13}$ Although this additional funding and national commitment is welcome, it will not, on its own, help enough smokers with mental health conditions to quit.

Smoking rates among people with mental health conditions will not reach the national ambition of $5 \%$ or less by 2030 without a trained workforce that sees smoking and smoking cessation as part of their role. The current lack of training in smoking cessation among the mental health workforce, as evidenced by trust and community surveys, is a problem that must be tackled if staff are to be able to deliver on these commitments.

Smokers expect doctors to ask them about smoking and deliver advice. If clinicians are not asking about smoking, it sends the signal that this is nothing to worry about. All psychiatrists should be able to deliver very brief advice, an evidence-based brief intervention on smoking that asks about smoking status, advises that support is available that will increase the chances of successfully stopping, and signposts smokers to further support. This is not designed to support someone through their quit attempt; it is about raising the issue and motivating smokers to try to quit.

Smokers with mental health conditions are likely to be more heavily addicted and therefore can find quitting harder. ${ }^{2}$ Ensuring that smokers with mental health conditions have access to the right pharmacotherapy to support them to quit is essential. Mental health trusts must ensure that the most effective treatments, including combination NRT and varenicline, are on their formularies and that they are being prescribed to patients in line with NICE guidance. ${ }^{27,53}$

Psychiatrists have a key role in reducing smoking among people with mental health conditions and in turn need appropriate training to deliver this. Although people can 
become immune to statistics about disease and death caused by smoking, reminding them about the effects that smoking has on well-being and quality of life is always worthwhile.

The number of people with mental health conditions pushed into poverty by smoking demands urgent action. Although quitting smoking will not solve poverty for everyone with a mental health condition, giving people the support they need to quit is a big step in the right direction.

\section{About the authors}

Vicky Salt is Policy Manager at Action on Smoking and Health, Hatton Garden, UK. Ciaran Osborne is Interim Director of Policy, Action on Smoking and Health, Hatton Garden, UK.

\section{Acknowledgements}

We thank Dr Peter Byrne of the Royal College of Psychiatrists.

\section{Author contributions}

V.S. led on the writing of this article, with input and review from C.O., who has been overseeing the work of the Mental Health and Smoking Partnership.

\section{Declaration of interest}

None.

ICMJE forms are in the supplementary material, available online at https:// doi.org/10.1192/bjb.2020.88.

\section{References}

1 Chang CK, Hayes R, Broadbent M, Perera G, Fernandes A, Lee W, et al. Life expectancy at birth for people with serious mental illness and other major disorders from a secondary mental health care case register in London. PLoS One 2011; 6(5): e19590.

2 Royal College of Physicians and Royal College of Psychiatrists. Smoking and Mental Health. Royal College of Physicians and Royal College of Psychiatrists, 2013.

3 Szatkowski L, McNeill A. Diverging trends in smoking behaviours according to mental health status. Nicotine Tob Res 2015; 3: 356-60.

4 Richardson S, McNeill A. Brose L. Smoking and quitting behaviours by mental health conditions in Great Britain (1993-2014). Addict Behav 2019; 90: 14-9.

5 NHS Digital. Statistics on Smoking - England. NHS Digital, 2019.

6 Action on Smoking and Health. The Impact of Smoking History on Employment Prospects, Earnings and Productivity: An Analysis using UK Panel Data. ASH, 2020.

7 Action on Smoking and Health. The Costs of Smoking to the Social Care System in England. ASH, 2019.

8 Action on Smoking and Health. Smoking and Poverty. ASH, 2019.

9 Office for National Statistics. Adult Smoking Habits in the UK 2018. ONS, 2019.

10 The Mental Health and Smoking Partnership. About us. Mental Health and Smoking Partnership (https://smokefreeaction.org.uk/smokefreenhs/smoking-and-mental-health/ [cited Nov 2019]).

11 Action on Smoking and Health. The Stolen Years: The Mental Health and Smoking Action Report. ASH, 2016.
12 Department of Health and Social Care. Towards a Smokefree Generation: A Tobacco Control Plan for England. Department of Health and Social Care, 2017.

13 NHS England. The NHS Long Term Plan. NHS England, 2019

14 Department of Health and Social Care. Advancing our Health: Prevention in the 2020s. Department of Health and Social Care, 2019.

15 NHS Digital. Adult Psychiatric Morbidity Survey: Survey of Mental Health and Wellbeing, England. 2014. NHS Digital, 2016.

16 Marmot M. Fair Society, Healthy Lives: The Marmot Review. Institute of Health Equity, 2010.

17 US Department of Health and Human Services. The Health Consequences of Smoking-50 Years of Progress: A Report of the Surgeon General. National Center for Chronic Disease Prevention and Health Promotion (US) Office on Smoking and Health, 2014.

18 Action on Smoking and Health. The Quitting Dividend for Tenants and Landlords. ASH, 2019.

19 Langley T. Mental Health, Smoking and Poverty in the UK: A Report Commissioned by Action on Smoking and Health and Public Health England. University of Nottingham, 2016.

20 OECD. Mental Health and Work. OECD Publishing, 2014.

21 Mind. Money and Mental Health. Mind (https://www.mind.org.uk/information-support/tips-for-everyday-living/money-and-mental-health/ money-and-mental-health/\#.XeFB9ej7QdU [cited Nov 2019])

22 Taylor G, McNeill A, Girling A, Farley A, Lindson-Hawley N, Aveyard P. Change in mental health after smoking cessation: systematic review and meta-analysis. BMJ 2014; 348: g1151.

23 McDermott MS, Marteau, TM, Hollands GJ, Hankins M, Aveyard P. Change in anxiety following successful and unsuccessful attempts at smoking cessation: cohort study. Br J Psychiatry 2013; 202(1): 62-7.

24 NHS Digital. Health Survey for England 2010. NHS Digital, 2011.

25 Nayak P, Pechacek T, Slovic P, Eriksen M. Regretting ever starting smoking: results from a 2014 national survey. Int J Environ Res Public Health 2017; 14(4): 390.

26 NHS England. Five Year Forward View for Mental Health. NHS England, 2016.

27 National Institute for Health and Care Excellence. Smoking: Acute, Maternity and Mental Health Services (PH48). NICE, 2013.

28 Action on Smoking and Health and Mental Health \& Smoking Partnership. Progress Towards Smokefree Mental Health Services: Findings from a Survey of Mental Health Trusts in England. ASH, 2019.

29 Robson D, Yates M, Tom J, Craig K, Healey A, McNeill A. Time to smoke: facilitating smoking breaks in mental health inpatient settings. Nicotine Tob Res 2016; 18(8): 1794-7.

30 Gunnell D, Irvine D, Wise L, Davies C, Martin M. Varenicline and suicidal behaviour: a cohort study based on data from the General Practice Research Database. BMJ 2009; 339: b3805.

31 Anthenelli R, Benowitz N, West R, Aubin L, McRae T, Lawrence D, et al. Neuropsychiatric safety and efficacy of varenicline, bupropion, and nicotine patch in smokers with and without psychiatric disorders (EAGLES): a double-blind, randomised, placebo-controlled clinical trial. Lancet 2016; 387: 2507-20.

32 Taylor G, Itani $T$, Thomas $K$, Rai $D$, Jones $T$, Windmeijer $F$, et al Prescribing prevalence, effectiveness, and mental health safety of smoking cessation medicines in patients with mental disorders. Nicotine Tob Res 2019; 22: 48-57.

33 Royal College of Psychiatrists. The Prescribing of Varenicline and Vaping (electronic cigarettes) to Patients with Severe Mental IIIness. RCPsych, 2019.

34 Public Health England. Evidence Review of E-Cigarettes and Heated Tobacco Products 2018. A Report Commissioned by Public Health England. 2018.

35 Royal College of Physicians. Nicotine Without Smoke: Tobacco Harm Reduction. RCP, 2016

36 Medicines and Healthcare Products Regulatory Agency. E-cigarettes: Regulations for Consumer Products. Medicines and Healthcare Products 
Regulatory Agency, 2016 (https://www.gov.uk/guidance/e-cigarettesregulations-for-consumer-products [cited Dec 2019])

37 McNeill A, Brose L, Calder R, Bauld L, Robson D. Vaping in England: An Evidence Update Including Mental Health and Pregnancy, March 2020. A Report Commissioned by Public Health England. Public Health England, 2020.

38 Action on Smoking and Health. Use of E-Cigarettes (Vapourisers) among Adults in Great Britain. ASH, 2019.

39 Smoking Toolkit Study. Trends in Electronic Cigarette Use in England. Smoking in England, 2019.

40 Hajek P, Philips-Waller A, Przulj D, Pesola F, Meyers-Smith K, Bisal N, et al. A randomized trial of E-cigarettes versus nicotine-replacement therapy. N Engl J Med 2019; 380: 629-37.

41 Jackson S, Shahab L, Kock L, West R, Brown J. Expenditure on smoking and alternative nicotine delivery products: a population survey in England. Addiction; 114: 2026-36.

42 Mental Health and Smoking Partnership. Use of Electronic Cigarettes by People with Mental Health Problems: A Guide for Health Professionals. Mental Health and Smoking Partnership, 2020.

43 Public Health England. Guidance: Using Electronic Cigarettes in NHS Mental Health Organisations. Public Health England, 2020 (https:// www.gov.uk/government/publications/e-cigarettes-use-by-patients-innhs-mental-health-organisations/using-electronic-cigarettes-in-nhsmental-health-organisations [cited Mar 2020]).

44 Action on Smoking and Health and Rethink. Smokefree Trusts: Making it Work for Service Users. ASH, 2019.

45 Public Health England. Guidance: Smoking Cessation in Secondary Care Mental Health Settings. Public Health England 2015 (https://www. gov.uk/government/publications/smoking-cessation-in-secondarycare-mental-health-settings [cited Mar 2020]).

46 House of Commons Library. Mental Health Statistics for England: Prevalence, Services and Funding. House of Commons Library, 2018.

47 Action on Smoking and Health. Smokefree Skills: Community Mental Health. ASH, 2019.

48 Kotz D, Brown J, West R. prospective cohort study of the effectiveness of smoking cessation treatments used in the "real world". Mayo Clin Proc 2014; 89(10): 1360-7.

49 Kotz D, Brown J, West R. 'Real-world' effectiveness of smoking cessation treatments: a population study. Addiction 2014; 109(3): 491-9.

50 Gilbody S, Peckham E, Man M-S, Mitchell N, Li J, Becque T. Bespoke smoking cessation for people with severe mental ill health (SCIMITAR): a pilot randomised controlled trial. Lancet Psychiatry 2015. (https://doi.org/10.1016/S2215-0366(15)00091-7).

51 Gilbody S, Peckham E, Bailey D, Brownings S, Fairhurst C, Heron P, et al. Smoking cessation for people with severe mental illness (SCIMITAR+): a pragmatic randomised controlled trial. Lancet Psychiatry 2019; 6(5): 379-90.

52 Kulkarni M, Huddlestone L, Taylor A, Ratschen E. A cross-sectional survey of mental health clinicians' knowledge, attitudes, and practice relating to tobacco dependence among young people with mental disorders. BMC Health Services Research 2014; 14: 618.

53 National Institute for Health and Care Excellence. Stop Smoking Interventions and Services (NG92). NICE, 2018.

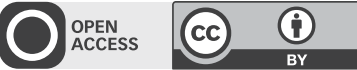

